\title{
Characterizing natal source population signatures in the diadromous fish Galaxias maculatus, using embryonic otolith chemistry
}

\author{
Nicole C. Barbee* ${ }^{*}$ Stephen E. Swearer \\ Department of Zoology, University of Melbourne, Parkville, Victoria 3010, Australia
}

\begin{abstract}
One of the greatest empirical challenges in studies of marine metapopulations is assessing the role of connectivity in maintaining local populations. The use of natural tags in body structures such as otoliths has led to significant improvements in our understanding of dispersal dynamics; however, the real knowledge gap remains our ability to identify the origins of dispersing larvae. In the present study we show that embryonic otoliths of a diadromous fish native to southeastern Australia, Galaxias maculatus, can be used to quantify unique natal elemental signatures and identify potential source populations spread out along a contiguous coastline. Using laser ablation inductively coupled plasma mass spectrometry (LA-ICPMS), we analysed embryonic otoliths from G. maculatus hatchlings from 10 rivers across coastal Victoria, Australia. We found significant differences among rivers in the concentrations of all 8 elements analysed ( $\mathrm{B}, \mathrm{Mg}, \mathrm{Mn}, \mathrm{Zn}, \mathrm{Cu}, \mathrm{Sr}, \mathrm{Ba}, \mathrm{Pb}$ ). More importantly, significant differences among rivers in the multi-element signature of hatchling otoliths indicate that sites separated by $10 \mathrm{~s}$ to $100 \mathrm{~s}$ of $\mathrm{km}$ can be discriminated with a high degree of confidence. Our results show that these methods can be successfully applied to examine questions of population connectivity within metapopulations of diadromous species.
\end{abstract}

KEY WORDS: Otolith chemistry $\cdot$ LA-ICPMS $\cdot$ Galaxias maculatus $\cdot$ Diadromy $\cdot$ Natal signatures

\section{INTRODUCTION}

In spatially fragmented aquatic environments such as streams (Downes \& Keough 1998) and coral reefs (Boehlert 1996), populations of many species with complex life cycles exist as a network of patches that are connected via dispersal: that is, a metapopulation. Empirical and theoretical studies of metapopulation dynamics have shown that the importance of dispersal to local population persistence depends on the degree of connectivity among populations (Hanski \& Gilpin 1997). Populations can be largely self-recruiting, meaning that individuals are born into and stay within that population, and thus are not reliant on dispersal for replenishment. At the other extreme, populations may be maintained primarily via dispersal from other populations and thus be dependent on connectivity with other populations. Most natural populations are likely maintained to varying degrees by both processes (Swearer et al. 2002). Because self-recruiting or demographically closed populations will be dynamically quite different from demographically open ones (Possingham \& Roughgarden 1990), determining the extent and conditions under which populations are replenished via dispersal vs. self-recruitment is critical for our understanding of the long term persistence of populations.

Local recruitment in marine systems has historically been attributed to the transport of larvae from nonlocal sources (Caley et al. 1996). However, a growing body of evidence suggests that local retention of larvae is a more pervasive phenomenon than previously thought (Swearer et al. 2002, Jones et al. 2005). This has led to a dramatic shift in thinking on how populations of many aquatic species are replenished, from an emphasis on widespread dispersal to a greater focus on 
the role of self-recruitment (Swearer et al. 2002, Levin 2006). Much of the recent evidence for significant levels of self-recruitment in marine populations comes from reef fish species with relatively short larval durations and highly specialized habitat requirements (e.g. Jones et al. 2005). Although these results are highly compelling for these species, it is unclear whether similar patterns will hold for species with much longer larval durations, and hence greater potential for dispersal (e.g. Warner et al. 2005).

Attempts to empirically quantify levels of exchange between local populations within a metapopulation have largely been hindered by the inherent difficulties of tracking small planktonic larvae. In recent years, considerable progress has been made using natural environmental markers to determine the sources of locally recruiting larvae. Otoliths, the balance structures in the inner ear of teleost fishes, have been particularly useful as recorders of the chemistry of the surrounding environment (Campana 1999). Otoliths are composed of calcium carbonate crystals (primarily aragonite) within a protein matrix. They are formed prior to birth and grow daily as new crystal layers are deposited around the existing core. During otolith growth, elements from the surrounding water can substitute for calcium and become permanently incorporated into the crystal (Campana 1999). Thus, otoliths function as daily recorders of the chemical environment experienced during the life of a fish. Otolith trace elemental signatures from natural populations have been successfully used for a variety of purposes, including identifying stocks (e.g. Campana et al. 1994) and juvenile nursery areas (e.g. Gillanders \& Kingsford 2000, Forrester \& Swearer 2002), as well as quantifying natal homing in migratory fishes (Thorrold et al. 2001) and larval retention in reef fish (Swearer et al. 1999).

The use of natural tags to identify sources of new recruits to a population, and hence determine levels of connectivity among local populations within a metapopulation, is dependent on the ability to discriminate among potential sources. To date, most studies have examined the core region of otoliths in juvenile or adult fish to make inferences about sources of origin (e.g. Campana et al. 1994, Patterson et al. 2004). A more accurate way of determining natal sources and their signatures is to collect larvae at the source, either before hatching or immediately upon hatching, before they have dispersed (Warner et al. 2005, Zacherl 2005, Chittaro et al. 2006). For most marine species this is virtually impossible because many are pelagic spawners, and even if pre-dispersing larvae are successfully collected, the amount of otolith material available for analysis may be prohibitively small. Detecting differences in natal otolith signatures in fish from sites along an open ocean coast where water masses are potentially more homogeneous can also be challenging (Patterson et al. 2004).

Some of the most successful attempts at distinguishing among populations have been in species of fish that spend some part of their lives in estuarine environments (Gillanders \& Kingsford 2000, Thorrold et al. 2001, Forrester \& Swearer 2002, Gillanders 2002). Because these systems tend to by highly influenced by freshwater inputs, there is the potential for large differences to exist in their water chemistries, which can then translate into greater differences in otolith signatures. Indeed, the relatively few studies that have used otolith chemistry to differentiate between fish populations in freshwater habitats have consistently found a high degree of discrimination among rivers (e.g. Thorrold et al. 1998, Wells et al. 2003, Crook \& Gillanders 2006).

As part of a larger study examining the metapopulation dynamics of a diadromous fish, Galaxias maculatus, we used otolith environmental signatures to determine the degree of connectivity among local populations of this species. Some of the unique features of the biology of this species have allowed us to overcome many of the problems associated with metapopulation studies of entirely marine species. G. maculatus is found in coastal draining rivers throughout southeastern Australia. This diadromous species migrates to estuaries to spawn, and larvae disperse out to sea where they spend a fairly protracted larval period of 3 to 5 mo before recruiting back into rivers (McDowall et al. 1994). Thus, each population of G. maculatus in a river is a discrete, spatially separated population within a large metapopulation of multiple rivers that are connected via a dispersive larval stage. Eggs of this species are readily collected in the tidal reaches of rivers, and can be reared and hatched in the lab (see 'Materials and methods'). Furthermore, with otoliths ranging between 20 to $30 \mu \mathrm{m}$, they offer sufficient material to analyse using laser ablation inductively coupled plasma mass spectrometry (LA-ICPMS). In addition, their association with individual rivers increases the likelihood of greater discriminatory power among potential sources using natural environmental tags incorporated into structures such as otoliths. Finally, because this species is short lived $(\sim 1 \mathrm{yr})$ and the spawning and recruitment periods are relatively discrete, we can be certain that the natal signatures derived from hatchlings will correspond to the range of potential signatures in subsequent recruits.

In this study, we show that otoliths obtained from Galaxias maculatus hatchlings from known locations can be used to discriminate among a large number of rivers separated by $10 \mathrm{~s}$ to $100 \mathrm{~s}$ of $\mathrm{km}$ along a contiguous coastline, and thus uniquely identify many poten- 
tial source populations. Our results suggest this to be a good model system for examining connectivity in a diadromous fish metapopulation. We also describe a new method for removing otoliths from newly hatched fish. Our method allows the removal of individual otoliths from individual hatchlings, thus eliminating some of the potential cross-contamination issues associated with the alternative method of batch processing of embryos for otolith extraction (e.g. Warner et al. 2005, Chittaro et al. 2006).

\section{MATERIALS AND METHODS}

Study species and collection of samples. Galaxias maculatus is one of the world's most widespread freshwater fish. It is found throughout the Southern Hemisphere, its range extending from southern Australia and New Zealand to the southern tip of South America. The main biogeographic region in Australia is in Victoria and New South Wales, but there are also disjunct populations in Western Australia and Tasmania (McDowall \& Frankenberg 1981). Recent molecular genetic analysis indicates considerable divergence among populations on different landmasses, which is consistent with restricted gene flow (Waters \& Burridge 1999). It is not known whether there is any genetic structure among mainland Australian populations, but populations in New Zealand are genetically homogeneous,

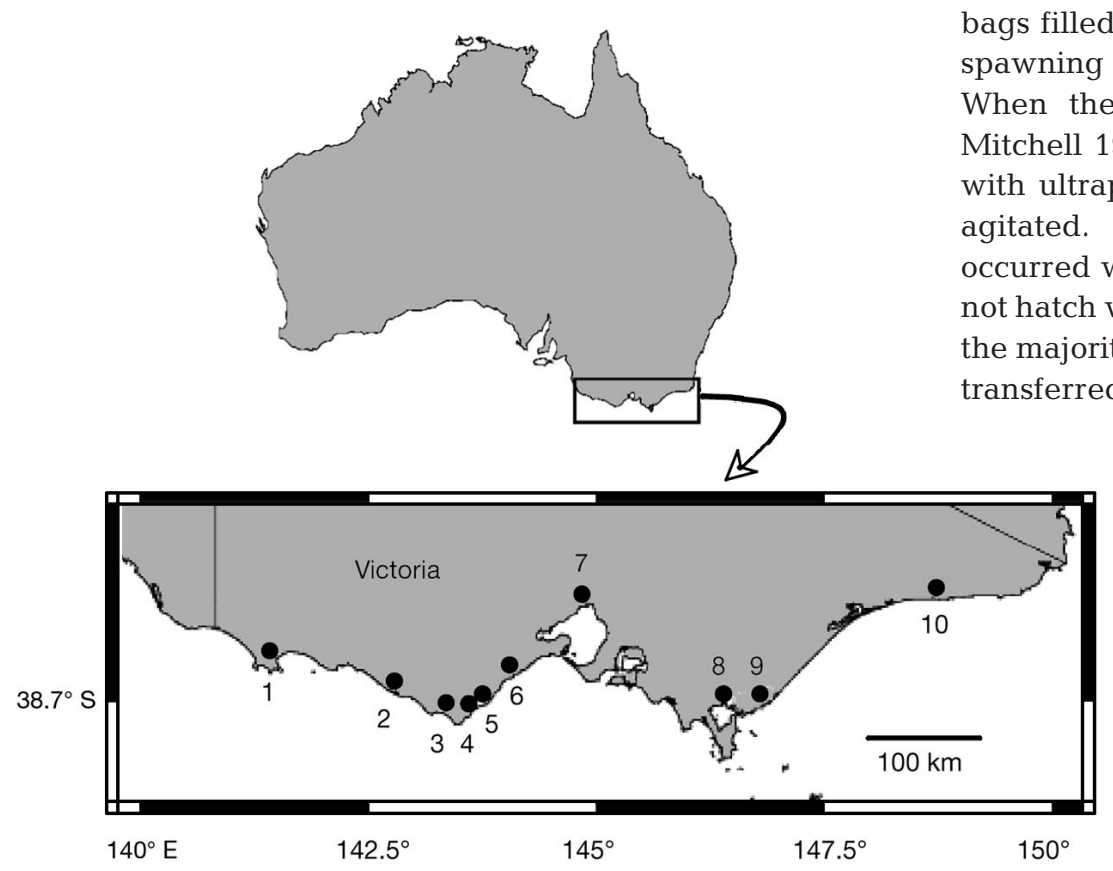

Fig. 1. Location of 10 rivers in Victoria, Australia, from which Galaxias maculatus eggs were collected. (1) Wattle Hill Creek, (2) Port Campbell Creek, (3) Aire River, (4) Barham River, (5) Wild Dog Creek, (6) Cumberland River, (7) Maribyrnong River, (8) Franklin River, (9) Tarra River, (10) Snowy River suggesting at least some larval exchange among populations at this scale (Waters et al. 2000).

Spawning in this species takes place from the late austral autumn to early winter, when adults migrate from their riverine habitats to spawn in the lower tidal reaches of rivers. Spawning occurs in the bankside vegetation that becomes submerged on spring tides, and the benthic eggs are attached to emergent vegetation (Benzie 1968). When the tides recede, eggs remain in the moist root environment of the vegetation and develop in air, until they are re-inundated by the next spring tide $(\sim 14 \mathrm{~d})$ and hatch. After hatching, the larvae disperse out to sea where they spend 3 to $5 \mathrm{mo}$ developing before recruiting en masse back into rivers starting in the austral spring (McDowall et al. 1994).

Galaxias maculatus eggs were collected from 10 rivers along the coast of Victoria, Australia, between May and July 2003 (Fig. 1). Previous observations indicated that the distribution of eggs in the bankside vegetation tends to be clumped and patchy (A. Hicks unpubl. data). We presumed that these clumps represent separate spawning events, and that most females likely release the majority of their eggs in 1 spawning rush. Therefore, to ensure that we included eggs from $>1$ female, we collected eggs from multiple clumps (hereafter called clutches) spread out over as large an area as possible within the spawning area. Each clutch sample consisted of 20 to 100 eggs, and 2 to 5 clutches were collected per river.

Eggs were brought back to the laboratory in plastic bags filled with soil and vegetation obtained from the spawning site, and kept at ambient temperature. the larvae were ready to hatch (based on 1989), eggs were placed in $20 \mathrm{ml}$ vials filled pure water (resistivity $>18 \mathrm{M} \Omega$ ) and gently Hatching of most of the larvae usually within minutes to a few hours. Eggs that did

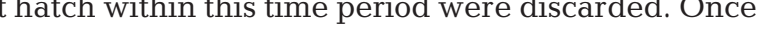
majority of larvae had hatched, all hatchlings were o a clean vial with fresh ultrapure water and frozen immediately for later otolith dissection. Thus, all the otolith material subsequently analysed was formed prior to hatching.

Otolith extraction, preparation and LAICPMS analysis. The otoliths (sagittae and lapilli) of Galaxias maculatus hatchlings were clearly visible inside the saccule and utricle of each ear of frozen specimens with a dissecting microscope fitted with a transmitting light source at $60 \times$ magnification (Fig. 2). Defrosted larvae were placed in individual droplets of $18 \mathrm{M} \Omega$ water on an acid-cleaned polystyrene tray. One sagittal otolith was removed from each 
hatchling with the aid of a fine-tipped tungsten pin, on which the tip had been bent slightly to form a hook (sagittae were distinguished from lapilli based on their position in the inner ear and their larger size). The otoliths were then lifted out of the water droplet using an acid-cleaned fine-tipped synthetic fiber paintbrush and transferred for cleaning to a droplet of ultrapure $15 \%$ $\mathrm{H}_{2} \mathrm{O}_{2}$ buffered with $0.1 \mathrm{~N} \mathrm{NaOH}$. After 15 min of cleaning, otoliths were similarly transferred through three 18 $\mathrm{M} \Omega$ water rinses, and finally placed onto a grided glass slide that had been coated with a thin layer of Buehler's Epo-Thin low viscosity resin. Each otolith was embedded in a tiny droplet of the same resin. Otoliths were obtained from between 19 and 25 individual hatchlings from each river, and hatchlings were selected from all available clutches.

Elemental analyses of hatchling otoliths were carried out on a Varian Inductively Coupled Plasma Mass Spectrometer (ICP-MS) fitted with a HelEx (Laurin Technic and the Australian National University) laser ablation (LA) system constructed around a Compex 110 (Lambda Physik) excimer laser operating at $193 \mathrm{~nm}$ (see Eggins et al. 1998 for a description of the LA system). Three NIST (National Institute of Standards and Technology) glass standards $(610,612,614)$ doped with trace elements at known concentrations were used to calibrate the system. Hatchling otoliths were run in blocks of 12 to 24 samples selected randomly for all sites and bracketed by analyses of the 3 standards. A 30 s blank was also acquired prior to each standard and sample analysis. Samples and standards were analysed in time-resolved mode, using a spot size of $19 \mu \mathrm{m}$, a laser energy setting of $\sim 40 \mathrm{~mJ}$ and a laser repetition rate of $3 \mathrm{~Hz}$. In the HelEx system, ablation is performed under pure He to minimise the re-deposition of ablated material (Eggins et al. 1998) and the sample is then rapidly entrained into the Ar carrier gas flow to the ICPMS. Each isotope was acquired for between 10 to $40 \mathrm{~ms}$, depending on count rate, resulting in a total scan time of $452 \mathrm{~ms}$. Using this method, we were able to quantify the concentrations of 8 elements $\left({ }^{11} \mathrm{~B},{ }^{24} \mathrm{Mg},{ }^{55} \mathrm{Mn},{ }^{63} \mathrm{Cu},{ }^{66} \mathrm{Zn},{ }^{88} \mathrm{Sr},{ }^{138} \mathrm{Ba}\right.$ and ${ }^{208} \mathrm{~Pb}$ ) in the embryonic otoliths (Table 1). Because hatchling otoliths are only 20 to $30 \mu \mathrm{m}$ in diameter, analysis of each sample consumed all material. Despite their small size, we obtained exceptionally high spatial resolution across the otolith with average acquisition times of $15 \mathrm{~s}$ (Fig. 3). Data were processed off-line using a macro template created in Excel. Data were first filtered to remove any spikes (a single scan value $>2 \times$ the median of the adjacent scans), smoothed (a running average of 3 scans), and the blank was then subtracted. Elemental concentrations were calculated using a single point calibration based on the NIST standard that most closely approximated the expected

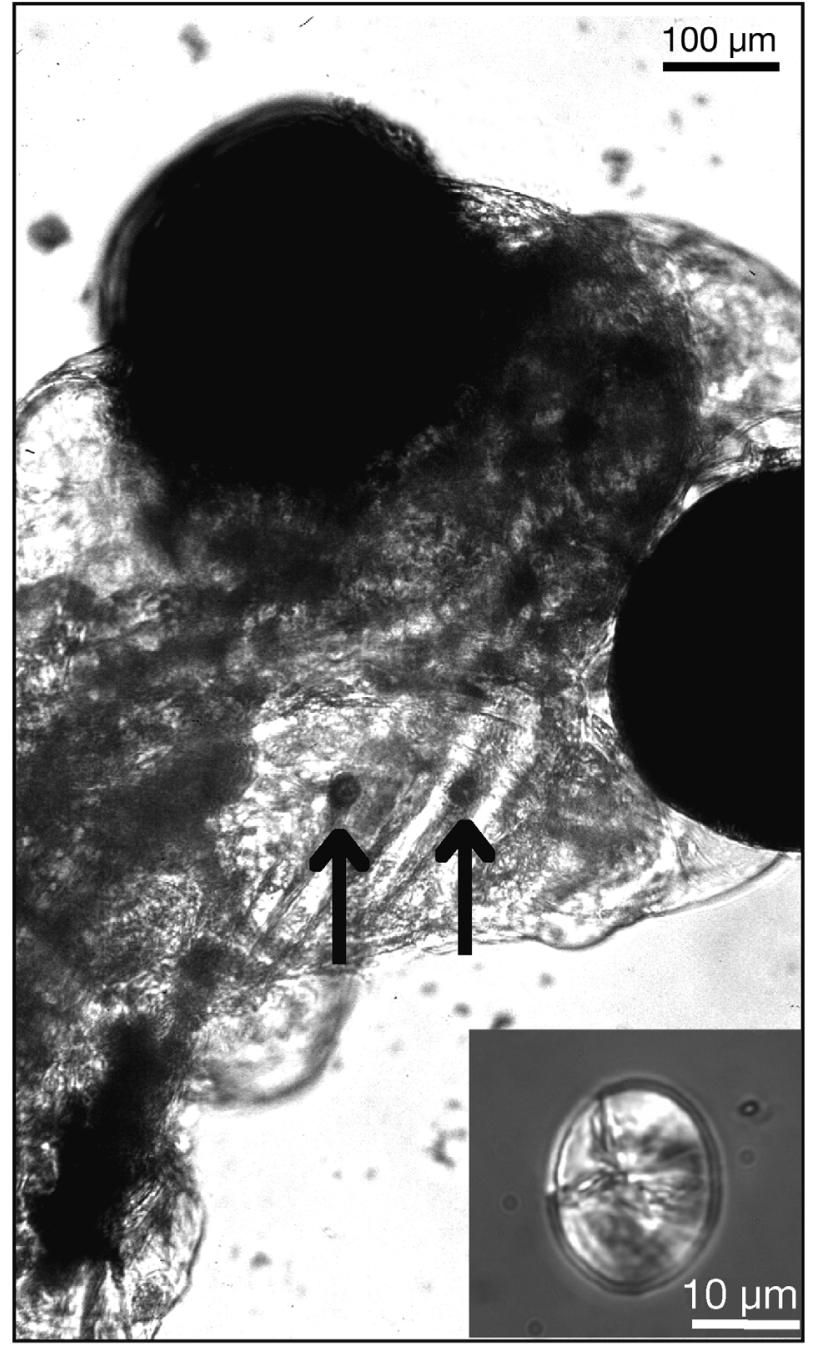

Fig. 2. Galaxias maculatus. Hatchling at $60 \times$ magnification, with sagitta and lapillus (indicated with arrows) clearly visible in the saccule and utricle. Inset is a hatchling sagittal otolith after removal at $400 \times$ magnification

concentration of a given element in otoliths, and expressed as molar ratios relative to $\mathrm{Ca}$ to control for variable ablation during analysis.

We observed high levels of spatial variability in elemental concentrations within otoliths (Fig. 3), with some elements, particularly Mn, exhibiting enrichment in the primordial region (consistent with other studies; Brophy et al. 2004, Ruttenberg et al. 2005). Consequently, we calculated otolith concentrations in 3 ways: the average concentration of the whole otolith, the average concentration in the non-primordial region, and the average concentration in the primordial region. The latter value was calculated by averaging the 5 to 7 scans surrounding the peak count rate in Mn. In contrast to other studies (e.g. Patterson et al. 2004), differences among populations in otolith ele- 
Table 1. Detection limits (DL) and precision estimates (\% relative standard deviation, RSD) for the LA-ICPMS analysis of the primordial region of Galaxias maculatus hatchling otoliths. DL based on 150 blank analyses (6 per block of samples) and expressed in molar ratios relative to mean Ca concentration in a sample. Precision estimates based on \%RSD of $>4000$ means of 6 scans (mean no. of scans used per sample), using the NIST (National Institute of Standards and Technology) standard that most closely approximated the concentration of each element in a sample

\begin{tabular}{|lcc|}
\hline Element & DL mol Ca & \%RSD \\
\hline $\mathrm{B}$ & $0.047\left(\times 10^{-3}\right)$ & 28.03 \\
$\mathrm{Mg}$ & $0.013\left(\times 10^{-3}\right)$ & 25.87 \\
$\mathrm{Mn}$ & $7.950\left(\times 10^{-6}\right)$ & 24.94 \\
$\mathrm{Cu}$ & $0.371\left(\times 10^{-6}\right)$ & 22.04 \\
$\mathrm{Zn}$ & $4.610\left(\times 10^{-6}\right)$ & 17.40 \\
$\mathrm{Sr}$ & $0.001\left(\times 10^{-3}\right)$ & 14.85 \\
$\mathrm{Ba}$ & $0.020\left(\times 10^{-6}\right)$ & 23.94 \\
$\mathrm{~Pb}$ & $0.057\left(\times 10^{-6}\right)$ & 44.85 \\
\hline
\end{tabular}

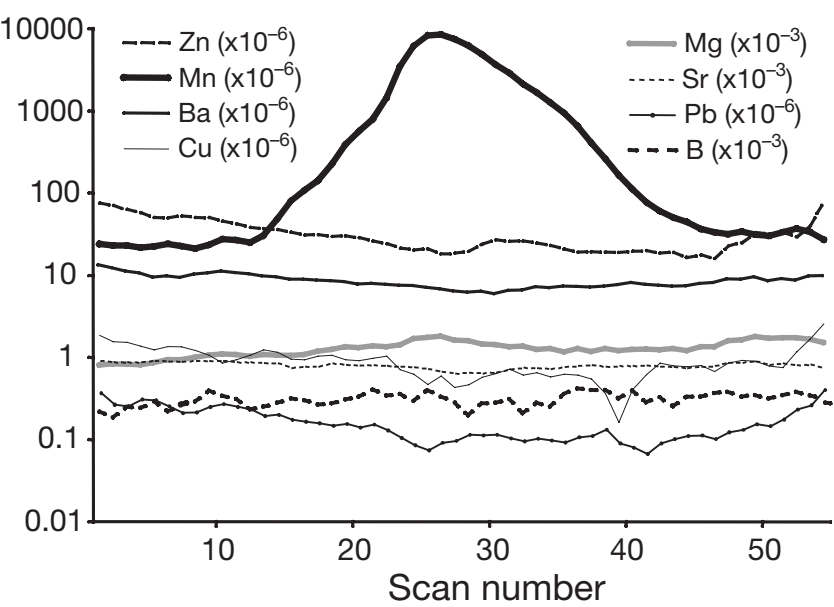

Fig. 3. Typical elemental profile through an otolith of a Galaxias maculatus hatchling

mental signatures were equally strong among the 3 data types, so we only present the results for the primordial region. The ability to detect differences among rivers in otolith primordia chemistry using this method is encouraging given the challenges posed by the inherently poor external precision associated with such short acquisition times (5 to 7 scans; Table 1).

Statistical analyses. Differences among rivers in the elemental concentration of hatchling otoliths were examined using ANOVA for each individual element. Where a significant difference in elemental concentration among rivers was observed, post hoc Tukey's Honestly Significant Difference (HSD) tests were performed to determine which rivers differed significantly from each other (all tests performed using JMP version 5.0.1.2). Prior to analyses, all data were examined for normality and homogeneity of variances using box plots and residuals plots (Quinn \& Keough 2002). To meet model assumptions, the data were either log transformed $(\mathrm{Mg}+1, \mathrm{Mn}, \mathrm{Zn}, \mathrm{Cu}+1, \mathrm{Ba})$ or 4 th-root transformed $(\mathrm{B}, \mathrm{Sr}, \mathrm{Pb}+0.1)$. We also performed a discriminate function analysis (DFA) of the multielemental signatures for each river and plotted the resulting DFA scores in order to visualize the spatial differences among rivers. The DFA also allowed us to test the reclassification success of hatchlings to sites of known origin. Cross validations were performed using jackknife procedures in Systat version 11.

We were also interested in determining how much variation clutches within rivers contributed to the overall variation in multi-element signatures. Unfortunately, at 3 rivers (Wattle Hill Creek, Aire River and Maribyrnong River), eggs from different clutches were all placed in the same bag, so we could not separate them out by clutch. This meant we could not analyse the effect of clutch among all rivers, so we ran a set of nested ANOVAs for each element on a subset of the data ( 7 rivers), with both river and clutch nested within river as random factors. Because this analysis did not include all rivers, and we were primarily interested in obtaining estimates of the amount of variation in hatchling otolith signatures that could be attributed to rivers and clutches nested within rivers, we report only the variance components for each of these terms for each element.

\section{RESULTS}

There were significant differences among rivers in the hatchling otolith concentration of all elements analysed individually, suggesting that this suite of elements can allow us to discriminate among rivers separated by $10 \mathrm{~s}$ to $100 \mathrm{~s}$ of $\mathrm{km}$ (Fig. 4, Table 2). Pair-wise comparisons revealed that differences among rivers varied for the different elements (Table 2). There were no clear broad-scale geographic patterns in the differences among rivers for any of the elements (Table 2).

There was also a high degree of discrimination among sites in the multi-elemental signatures of otoliths, as illustrated in the DFA plot (Fig. 5), which shows a minimal overlap of the $95 \%$ confidence ellipses around the means for most sites. Together, the first 2 discriminant functions accounted for $85 \%$ of the variation among rivers, with Sr contributing most to river differentiation on Discriminant Function (DF), and B contributing most to DF 2 (see Fig. 5 legend). The overall reclassification rate was quite good (72\%), with some sites showing an extremely high degree of successful reclassification (i.e. Tarra River $=91 \%$ ), and others showing less successful reclassification rates (i.e. Port Campbell Creek $=53 \%$ ) (see Fig. 5 legend). 
Variation among egg clutches within rivers contributed 3.3 to $33.0 \%$ of the variation observed in the otolith concentration of individual elements (Table 2). The 2 elements that showed the greatest variability among clutches within rivers were $\mathrm{Zn}$ and $\mathrm{Pb}$, both of which contributed little to overall site discrimination. Variation among rivers contributed 2.3 to $73.3 \%$ of the variation in otolith element concentration. As expected, the 2 elements that showed the largest components of variance attributed to rivers ( $\mathrm{Sr}$ and $\mathrm{B}$ ) were the 2 elements that contributed most to site separation in the DFA.
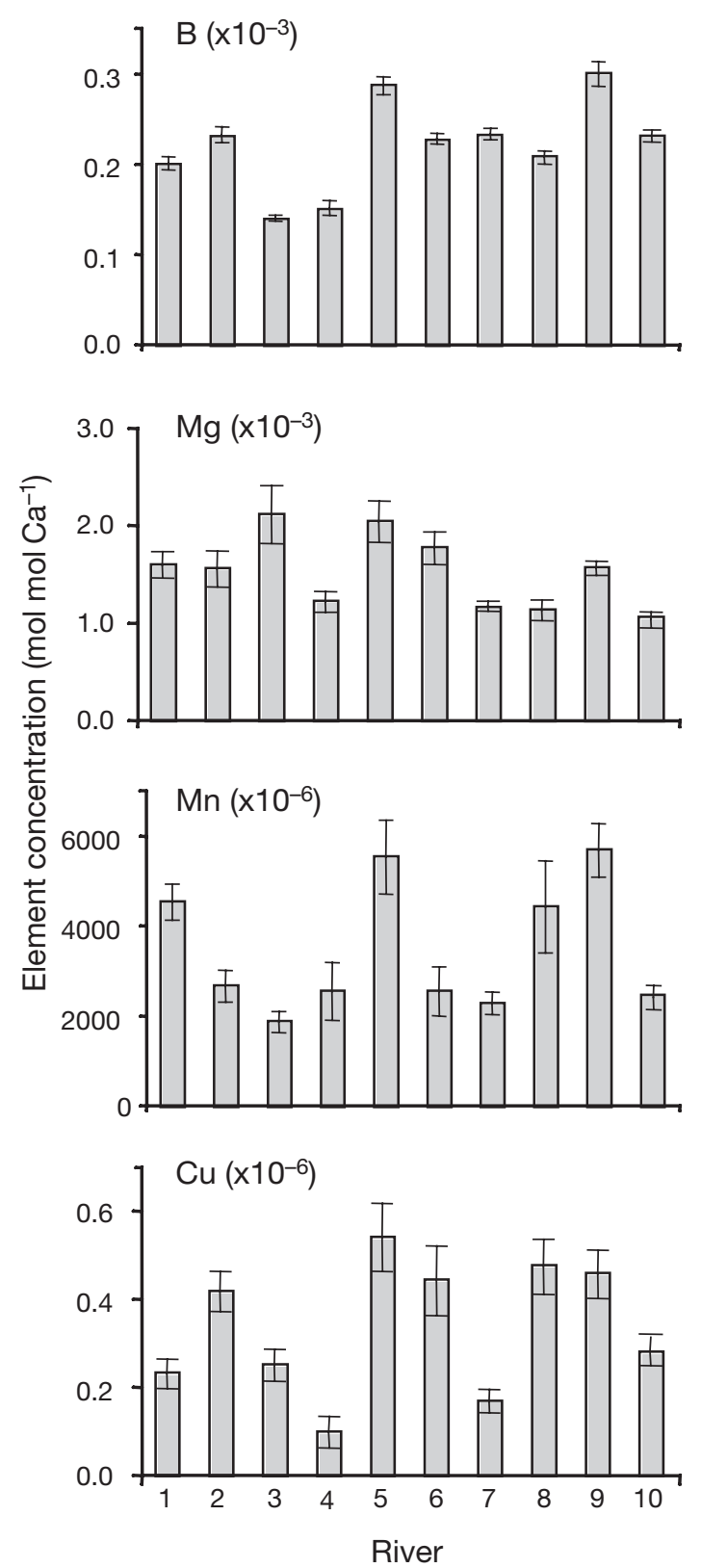

\section{DISCUSSION}

One of the fundamental unanswered questions in ecology is: What are the sources of recruitment for populations of species with highly dispersive offspring? Progress in this area has been hindered by our inability to successfully identify the origins of dispersing larvae. Using the otoliths of hatchlings of the diadromous fish Galaxias maculatus, we showed that unique environmental signatures can be identified for a large number of potential source populations (rivers) and that a high degree of discrimination is possible among
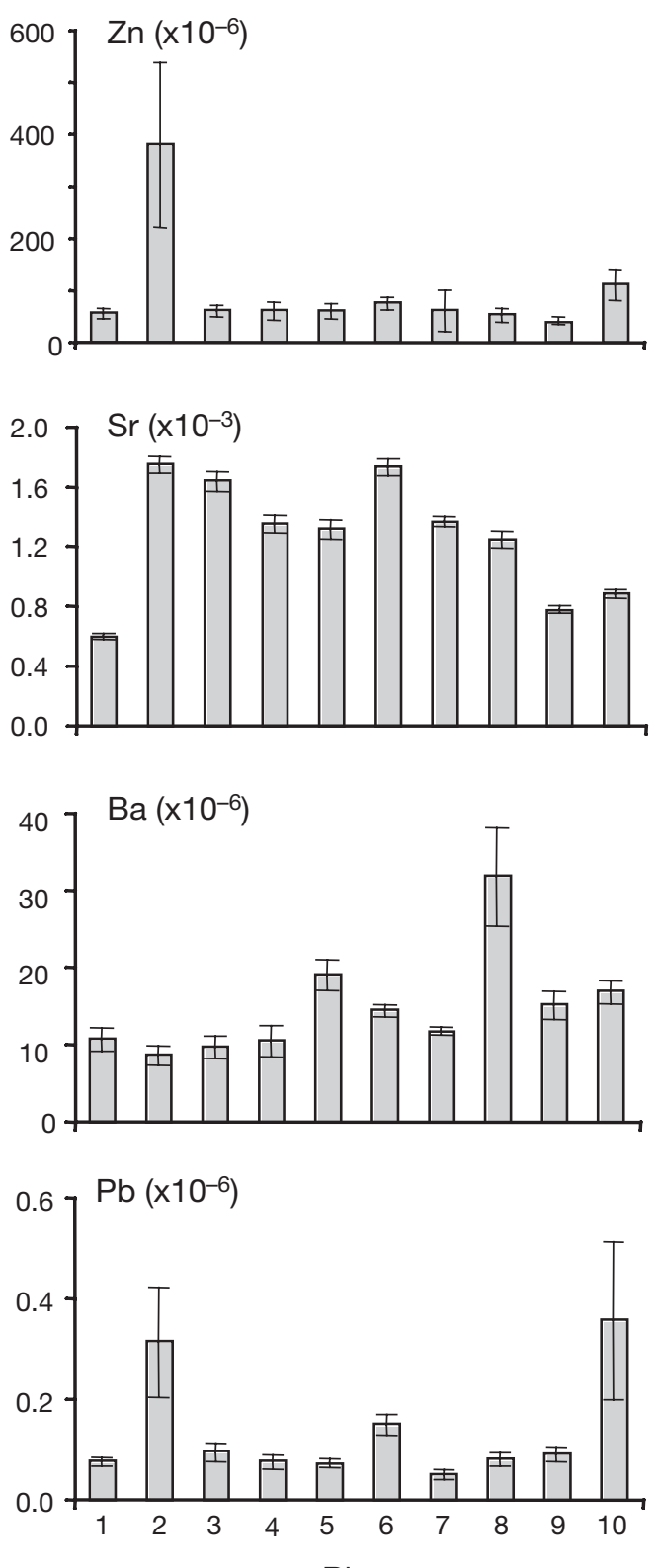

River

Fig. 4. Mean $( \pm \mathrm{SE})$ element concentrations in otoliths of Galaxias maculatus hatchlings from each of the sampled rivers. Rivers are ordered geographically along the $x$-axis from west (left) to east (right). See Fig. 1 for river numbers 
Table 2. Results from 1-way ANOVA testing for differences among sites in the concentration of each element (relative to mean Ca concentration) in hatchling otoliths. 'Pair-wise comparisons' indicate which sites were significantly different from each other (Tukey's HSD): numbers refer to sites; ${ }^{*} p<0.0001$ as in Fig. $1_{i}$ lines under numbers link sites that were not significantly different from each other $(\mathrm{p}>0.05)$. Also included are variance components (as \% of total) for the 2 factors River and Clutch(River) in nested ANOVAs performed on a subset of rivers

\begin{tabular}{|c|c|c|c|c|c|c|c|}
\hline \multirow[t]{2}{*}{ Element } & \multirow[t]{2}{*}{ Source } & \multirow[t]{2}{*}{ df } & \multirow[t]{2}{*}{ SS } & \multirow[t]{2}{*}{$F$} & \multirow[t]{2}{*}{ Pair-wise comparisons } & \multicolumn{2}{|c|}{ Variance components ${ }^{\mathrm{a}}$} \\
\hline & & & & & & River & Clutch (River) \\
\hline \multirow[t]{2}{*}{ B } & River & 9 & 0.339 & $44.899^{*}$ & $\underline{95} \underline{710268} 1 \underline{43}$ & 47.2 & 22.3 \\
\hline & Error & 209 & 0.175 & & & & \\
\hline \multirow[t]{2}{*}{$\mathrm{Mg}$} & River & 9 & 0.683 & $6.639^{*}$ & 35691247810 & 19.7 & 15.0 \\
\hline & Error & 209 & 2.390 & & & & \\
\hline \multirow[t]{2}{*}{$\mathrm{Mn}$} & River & 9 & 6.367 & $6.353^{*}$ & 91582107463 & 16.0 & 3.7 \\
\hline & Error & 209 & 23.273 & & & & \\
\hline \multirow[t]{2}{*}{$\mathrm{Cu}$} & River & 9 & 0.434 & $9.547^{*}$ & $\underline{58962} 103174$ & 21.9 & 6.7 \\
\hline & Error & 209 & 1.057 & & & & \\
\hline \multirow[t]{2}{*}{$\mathrm{Zn}$} & River & 9 & 10.636 & $6.140^{*}$ & $\underline{2106} 3541897$ & 2.2 & 33.0 \\
\hline & Error & 209 & 40.230 & & & & \\
\hline \multirow[t]{2}{*}{$\mathrm{Sr}$} & River & 9 & 1.715 & $89.578^{*}$ & 62374581091 & 73.3 & 3.3 \\
\hline & Error & 209 & 0.445 & & & & \\
\hline \multirow[t]{2}{*}{$\mathrm{Ba}$} & River & 9 & 5.692 & $10.508^{*}$ & $\underline{85106} 971432$ & 26.9 & 16.3 \\
\hline & Error & 209 & 12.580 & & & & \\
\hline \multirow[t]{2}{*}{$\mathrm{Pb}$} & River & 9 & 0.369 & $5.027^{*}$ & $\underline{2106} 9381457$ & 3.3 & 32.0 \\
\hline & Error & 209 & 1.704 & & & & \\
\hline
\end{tabular}

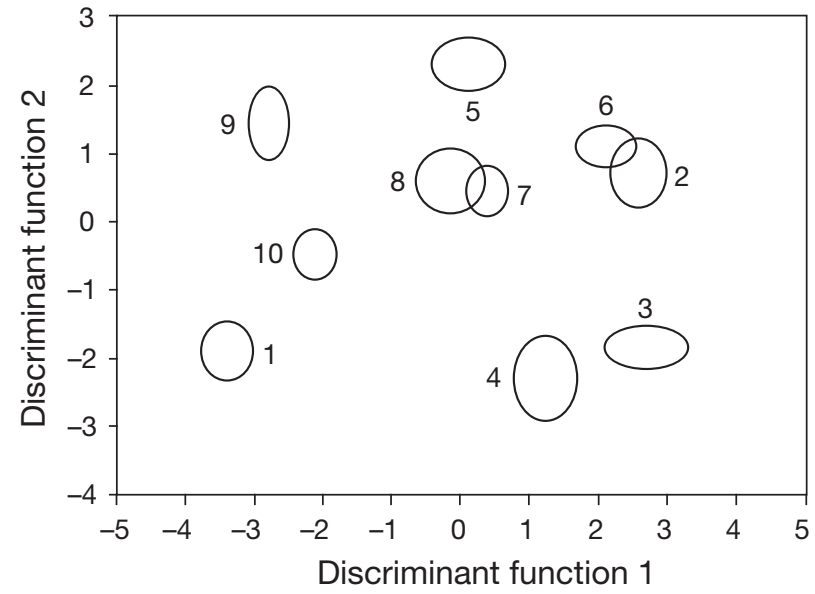

Fig. 5. Discriminant Function Analysis (DFA) of hatchling otoliths. DF 1 weights - Sr: 1.03; Ba: -0.33 ; B: -0.26 ; Mn: 0.17; Zn: $0.14 ; \mathrm{Cu}: 0.13 ; \mathrm{Mg}: 0.11$; Pb: -0.10 . DF 2 weights - B: 0.83; $\mathrm{Cu}: 0.52$; Sr: 0.34; Zn: -0.31 ; Ba: 0.22 ; Mn: 0.18 ; Pb: -0.06 ; Mg: 0.01 . Reclassification success rates for each site using jackknife cross-validation procedures were: (1) Wattle Hill Creek, $83 \%$, (2) Port Campbell Creek, 53\%; (3) Aire River, 70\%; (4) Barham River, $79 \%$; (5) Wild Dog Creek, 60\%; (6) Cumberland River, $62 \%$; (7) Maribyrnong River, $83 \%$; (8) Franklin River, $57 \%$; (9) Tarra River, $91 \%$; (10) Snowy River, $82 \%$

populations separated by 10 s to 100 s of $\mathrm{km}$ of contiguous coastline. The few other studies that have examined the utility of using otoliths from pre-dispersing larvae to identify source populations have similarly found that unique natal signatures can be used to dis- criminate among sites; however, their discriminatory power has been limited to either a regional scale (Warner et al. 2005) or to the site-within-region scale (Ruttenberg \& Warner 2006). Our results suggest that these methods can be successfully applied to examine questions of population connectivity in G. maculatus and other diadromous species.

All 8 elements analysed in the hatchling otoliths of Galaxias maculatus showed highly significant differences among the 10 sampled sites (Fig. 4). Furthermore, all 10 sites showed significant levels of differentiation in the multi-elemental signature of hatchling otoliths and good overall assignment success (Fig. 5). Given the inherently poor precision associated with characterizing elemental signatures in otolith primordia (see 'Materials and methods' and Table 1), our ability to discriminate with the observed degree of confidence among this many sites is worth highlighting, particularly in light of comparable reclassification rates observed in other studies that integrated greater amounts of material from either the larval (Patterson et al. 2004) or juvenile (Gillanders \& Kingsford 2000) portion of the otolith. Interestingly, many of the studies that obtained greater reclassification success rates based on otolith elemental signatures typically included 5 or fewer sites in their analyses (e.g. Thorrold et al. 1998, Wells et al. 2003). In the few cases where $>5$ sites were sampled, sites were either grouped to examine larger geographic (i.e. regional) patterns (e.g. Hamer et al. 2003, Ruttenberg \& Warner 2006), or reassignment suc- 
cess using a DFA or similar test was not performed (Gillanders 2002). We argue that, all else being equal, classification success rates will decrease as the number of sites included in the analysis increases (see Smouse et al. 1982). In 50 iterations of the DFA on random combinations of 5 of our 10 sites, we obtained an improved overall mean reassignment success rate of $81 \%$. The increase in discriminatory power with a smaller number of sites likely occurs because the DFA weights each element to maximize the ratio of between-group variance to within-group variance for all sites sampled. As more sites are added to the model, elements that were important in separating a few sites can become less important than elements that contribute to overall separation of sites, resulting in greater overlap of neighbouring sites in DF space. Thus, with 10 sites included in our analysis, our average of a $72 \%$ chance of correct reassignment to sites of know origin is compelling evidence for the utility of these methods for identifying sources of dispersing larvae.

The geographic scale of differentiation among sites that we observed in the present study bodes well for future studies of population connectivity in Galaxias maculatus. Ultimately, our aim is to examine the natal signature at the core of otoliths of recruits that are migrating back into freshwater habitats after their pelagic larval period (i.e. the portion of the otolith that is laid down during the embryonic stage), and compare these to the signatures of hatchlings from known sources. To our knowledge, and despite the recurrent emphasis on the importance of this type of data in marine and fisheries research (Sale et al. 2005), this has only been attempted in 1 study (Ruttenburg \& Warner 2006). These authors appropriately warned that using these methods for addressing questions about population connectivity will only be appropriate if the scale of variability in otolith chemistry matches the scale of dispersal in the species of interest. G. maculatus has one of the broadest distributions of any freshwater fish in the world. Although we are currently unsure of the scales of dispersal in this species, evidence from genetic studies suggests that there is little dispersal at the betweencontinent scale, but that extensive dispersal may occur at the within-continent scale (Waters et al. 2000). Our sites cover a considerable portion of the main biogeographic range of G. maculatus in Australia (McDowall $\&$ Frankenburg 1981). Given that we achieved high discriminatory power among sites across this range, this suggests that the application of these methods at the scale of our present study is appropriate. Nonetheless, the development of a more complete library of source signatures would need to include sites in Tasmania and southern New South Wales. The fact that spawning sites are limited to the tidal reaches of coastal rivers and eggs can be readily collected from the exposed roots of bankside vegetation at low tide makes this undertaking entirely tractable and feasible.

While other studies that examined the otolith elemental signatures of pre-dispersing larvae found high levels of variation among clutches (Warner et al. 2005, Ruttenberg \& Warner 2006), we did not find that variation in elemental concentrations among clutches within rivers obscured differences among rivers. With the exception of $\mathrm{Zn}$ and $\mathrm{Pb}$, very little of the variation in otolith elemental concentrations was attributable to differences among clutches (Table 2). $\mathrm{Zn}$ and $\mathrm{Pb}$ are notoriously difficult elements to measure in otoliths because background levels are typically high relative to sample levels and there is a high likelihood of contamination. Not unexpectedly, these elements did not contribute strongly to site discrimination. Most of the elements that did contribute more strongly to site discrimination ( $\mathrm{Sr}$ and $\mathrm{Ba}$ for $\mathrm{DF} 1, \mathrm{~B}$ and $\mathrm{Cu}$ for $\mathrm{DF} 2$ ) showed little among-clutch variation (Table 2). The exception was $B$, which did show a moderate amount of variation among clutches, but the variation attributable to rivers was 2 times that attributable to clutches, and clearly more important at explaining the overall differences among samples.

One of the factors that may contribute to the high among-clutch variability observed in previous studies could be the batch processing methods used for sample preparation. While this method may have the advantage of reducing sample processing time (Chittaro et al. 2006), it increases the possibility of crosscontamination between otoliths within the same batch (i.e. clutch) because all otoliths are extracted and cleaned in the same liquid. In our method, each otolith was individually removed and cleaned, thus minimising the potential for cross-contamination. Batch processing may have the effect of homogenising within-clutch variation, thus emphasising the between-clutch variation, whereas individual otolith processing better captures the variation within a clutch, which may reduce differences among clutches. Another disadvantage of batch processing is that some of the otoliths analysed might be from the same fish, which means that some of the within-clutch samples may not be truly independent. This might also contribute to the homogenisation of within-clutch variation. Because we are able to remove individual otoliths from individual hatchlings, we are able to better avoid these potentially confounding sources of error. Nonetheless, we recognise that for species that are hard to rear in the laboratory until hatching, or in which otolith are not readily visible inside the specimen, batch processing may be the most effective means of obtaining calcified embryonic structures.

The challenge that remains is the determination of whether these natal signatures can be successfully 
used to identify the sources of recruiting Galaxias maculatus, and thus give us some indication of the role of dispersal in the metapopulation dynamics of this species. A first consideration is the well-documented lack of temporal consistency in otolith signatures (e.g. Gillanders \& Kingsford 2000, Gillanders 2002), which can limit the broad applicability of these methods. Because G. maculatus is an annual species, we can be confident that the hatchlings obtained in any given year will correspond to the recruits collected in the subsequent recruitment season. Furthermore, the accessibility of spawning sites, and the fact that all recruits must enter through the river mouth and do so within 3 to 5 mo of being spawned, means that both these populations can be easily sampled. Finally, the massive biogeographic range of this species makes the task of sampling all potential populations seem daunting. However, as discussed previously, dispersal across major oceanic basins (i.e. the Tasman Sea) is unlikely to be demographically relevant. By broadening our scope to include sites throughout southeastern Australia, including Tasmania, we feel confident that we can capture a significant representation of source populations. The use of more robust statistical techniques, such as Bayesian assignment tests (Manel et al. 2002) that allow for the incorporation of the probability associated with an individual not being from a known or identifiable site, also holds promise for improving the inferential power of these techniques.

Acknowledgements. We thank A. Hicks, J. Morrongiello and D. Semmens for helping us find our very first Galaxias maculatus eggs, and for contributing to our egg collections. We also thank A. Hicks for access to his unpublished data, and 2 anonymous reviewers for comments that helped improve the manuscript. Funding for this project was provided by an Australian Research Council Discovery Grant to S.E.S., and an Australian Government grant through the Natural Heritage Trust/National Action Plan (multi-regional component) to N.C.B.

\section{LITERATURE CITED}

Benzie V (1968) Some ecological aspects of the spawning behaviour and early development of the common whitebait, Galaxias maculatus attenuatus (Jenyns). Proc NZ Ecol Soc 15:31-39

Boehlert GW (1996) Larval dispersal and survival in tropical reef fishes. In: Polunin NVC, Roberts CM (eds) Reef fisheries. Chapman \& Hall, London, p 61-84

Brophy D, Jeffries TE, Danilowicz BS (2004) Elevated manganese concentrations at the cores of clupeid otoliths: possible environmental, physiological, or structural origins. Mar Biol 144:779-786

Caley MJ, Carr MH, Hixon MA, Hughes TP, Jones GP, Menge BA (1996) Recruitment and the local dynamics of open marine populations. Annu Rev Ecol Syst 27:477-500

Campana SE (1999) Chemistry and composition of fish otoliths: pathways, mechanisms and applications. Mar Ecol Prog Ser 188:263-297

Campana SE, Fowler AJ, Jones CM (1994) Otolith elemental fingerprinting for stock identification of Atlantic cod (Gadus morhua) using laser ablation ICPMS. Can J Fish Aquat Sci 51:1942-1950

Chittaro PM, Hogan JD, Gagnon J, Fryer BJ, Sale PF (2006) In situ experiment of ontogenetic variability in the otolith chemistry of Stegastes partitus Mar Biol 149:1227-1235

Crook DA, Gillanders BM (2006) Use of otolith chemical signatures to estimate carp recruitment sources in the midMurray River, Australia. River Res Appl 22:871-879

Downes BJ, Keough MJ (1998) Scaling of colonization processes in streams: parallels and lessons from marine hard substrata. Aust J Ecol 23:8-26

Eggins SM, Kinsley LPJ, Shelley JMG (1998) Deposition and element fractionation processes during atmospheric pressure laser sampling for analysis by ICP-MS. Appl Surf Sci 129:278-286

Forrester GE, Swearer SE (2002) Trace elements in otoliths indicate the use of open-coast versus bay nursery habitats by juvenile California halibut. Mar Ecol Prog Ser 241:201-213

Gillanders BM (2002) Temporal and spatial variability in elemental composition of otoliths: implications for determining stock identity and connectivity of populations. Can J Fish Aquat Sci 59:669-679

Gillanders BM, Kingsford MJ (2000) Elemental fingerprints of otoliths of fish may distinguish estuarine 'nursery' habitats. Mar Ecol Prog Ser 201:273-286

Hamer PA, Jenkins GP, Gillanders BM (2003) Otolith chemistry of juvenile snapper Pagrus auratus in Victorian water: natural chemical tags and their temporal variation. Mar Ecol Prog Ser 263:261-273

Hanski IA, Gilpin ME (1997) Metapopulation biology. Academic Press, San Diego, CA

Jones GP, Planes S, Thorrold SR (2005) Coral reef fish larvae settle close to home. Curr Biol 15:1314-1318

Levin LA (2006) Recent progress in understanding larval dispersal: new directions and digressions. Integr Comp Biol 46:282-297

Manel S, Berthier P, Luikart G (2002) Detecting wildlife poaching: identifying the origin of individuals with Bayesian assignment tests and multilocus genotypes. Conserv Biol 16:650-659

McDowall RM, Frankenberg RS (1981) The galaxiid fishes of Australia (Pisces: Galaxiidae). Rec Aust Mus 33:443-605

McDowall RM, Mitchell CP, Brothers EB (1994) Age at migration from the sea of juvenile Galaxias in New Zealand (Pisces: Galaxiidae). Bull Mar Sci 54:385-402

Mitchell CP (1989) Laboratory culture of Galaxias maculatus and potential applications. NZ J Mar Freshw Res 23: 325-336

Patterson HM, Kingsford MJ, McCulloch MT (2004) Elemental signatures of Pomacentrus coelestis otoliths at multiple spatial scales on the Great Barrier Reef, Australia. Mar Ecol Prog Ser 270:229-239

Possingham HP, Roughgarden J (1990) Spatial population dynamics of a marine organism with a complex life cycle. Ecol 71:973-985

Quinn GP, Keough MJ (2002) Experimental design and data analysis for biologists. Cambridge University Press, Cambridge

Ruttenberg BI, Warner RR (2006) Spatial variation in the chemical composition of natal otoliths from a reef fish in the Galápagos Islands. Mar Ecol Prog Ser 328:225-236

Ruttenberg BI, Hamilton SL, Hickford MJH, Paradis G, Sheehy M, Standish JD, Ben-Tzvi O, Warner RR (2005) 
Elevated levels of trace elements in cores of otoliths and their potential use as natural tags. Mar Ecol Prog Ser 297: 273-281

Sale PF, Cowen RK, Danilowicz BS, Jones GP and 7 others (2005) Critical science gaps impede use of no-take fishery reserves. Trends Ecol Evol 20:74-80

Smouse PE, Spielman RS, Park MH (1982) Multiple-locus allocation of individuals to groups as a function of the genetic variation within and differences among human populations. Am Nat 119:445-463

Swearer SE, Caselle JE, Lea DW, Warner RR (1999) Larval retention and recruitment in an island population of a coral-reef fish. Nature 402:799-802

Swearer SE, Shima JS, Hellberg ME, Thorrold SR and 6 others (2002) Evidence of self-recruitment in demersal marine populations. Bull Mar Sci 70:251-271

Thorrold SR, Jones CM, Campana SE, McLaren JW, Lam JWH (1998) Trace element signatures in otoliths record natal river of juvenile American shad Alosa sapidissima. Limnol Oceanogr 43:1826-1835

Thorrold SR, Latkoczy C, Swart PK, Jones CM (2001) Natal

Editorial responsibility: Steven Morgan (Contributing Editor), Bodega Bay, California, USA homing in a marine fish metapopulation. Science 291: 297-299

Warner RR, Swearer SE, Caselle JE, Sheehy M, Paradis G (2005) Natal trace-elemental signatures in the otoliths of an open-coast fish. Limnol Oceanogr 50:1529-1542

Waters JM, Burridge CP (1999) Extreme intraspecific mitochondrial DNA sequence divergence in Galaxias maculatus (Osteichthys: Galaxiidae), one of the world's most widespread freshwater fish. Mol Phylogen Evol 11:1-12

Waters JM, Dijkstra LH, Wallis GP (2000) Biogeography of a southern hemisphere freshwater fish: how important is marine dispersal? Mol Ecol 9:1815-1821

Wells BK, Rieman BE, Clayton JL, Horan DL, Jones CM (2003) Relationships between water, otolith, and scale chemistries of westslope cutthroat trout from the Coeur d'Alene River, Idaho: the potential application of hard-part chemistry to describe movements in freshwater. Trans Am Fish Soc 132:409-424

Zacherl DC (2005) Spatial and temporal variation in statolith and protoconch trace elements as natural tags to track larval dispersal. Mar Ecol Prog Ser 290:145-163

Submitted: August 3, 2006; Accepted: January 25, 2007

Proofs received from author(s): July 16, 2007 